Research Article

\title{
Tunnel Construction Workers' Cognitive Biases and Unsafe Behaviors: The Mediating Effects of Risk Perceptions
}

\author{
Hujun Li $\mathbb{D},{ }^{1}$ Huihua Chen, ${ }^{1}$ Zhengyu Zhao, ${ }^{1,2}$ Xiaodong Hu, ${ }^{1}$ Baoquan Cheng $\mathbb{D},{ }^{1}$ \\ and Jianling Huang $\mathbb{B}^{1}$ \\ ${ }^{1}$ Department of Engineering Management, School of Civil Engineering, Central South University, Changsha, \\ Hunan 410075, China \\ ${ }^{2}$ Hangzhou Urban Construction Development Group Co., Ltd., Hangzhou, Zhejiang 310000, China
}

Correspondence should be addressed to Jianling Huang; hjl1201@csu.edu.cn

Received 11 September 2020; Revised 9 October 2020; Accepted 26 October 2020; Published 10 November 2020

Academic Editor: Yilin Gui

Copyright (c) 2020 Hujun Li et al. This is an open access article distributed under the Creative Commons Attribution License, which permits unrestricted use, distribution, and reproduction in any medium, provided the original work is properly cited.

The poor safety performance of the construction industry is a global concern. Workers' unsafe behaviors (WUBs) are viewed as critical causes of construction accidents. Thus, it has been a leading research topic to identify antecedents of WUBs and establish reliable models to explain WUBs. Cognitive biases (CBs) are salient antecedents of WUBs. However, the relationships between CBs and WUBs are not further explored in construction safety management. As such, this study selected three prevalent CBs, i.e., availability bias (AB), confirmation bias (FB), and overconfidence, and investigated the relationships between the three CBs and WUBs and the functions of RPs in these relationships among tunnel construction workers. We established six multiple regression models. Research results show that CBs can directly influence RPs and WUBs, RPs are antecedents of WUBs, and the mediating effect of RPs on the relationships between CBs and WUBs is salient. In detail, AB and FB explain more ERP and overconfidence explains more BRP. AB and FB indirectly influence more WUBs through ERP, while overconfidence indirectly affects more WUBs through BRP. The study provides a novel theoretical paradigm for conceptualizing CBs and their relationships with RPs and WUBs. The research results can also guide managers to take debiasing measures to decrease workers' unsafe behaviors on the construction site.

\section{Introduction}

The construction works have always been criticized for high injury and fatality rates across the world, and construction accidents caused huge losses to the government, industry, enterprises, and the workers themselves [1-3]. According to the statistic of China's Ministry of Housing and Urban Rural Development (MHURD), 773 accidents resulted in 904 deaths in the construction and municipal engineering sector in 2019 [4]. Similar statistics were also settled in other countries or regions such as the U.S. where 39.7 thousand cases occurred in building construction in 2018 [5]. In Hong Kong, the construction industry had 2,974 accidents and 16 deaths in 2019 [6]. In Singapore, the Workplace Safety and Health (WSH) reported 13 fatal injuries and 121 major injuries in the construction industry in 2019 [7]. Among the different types of construction works, tunnel construction works are with higher safety risks $[8,9]$. The reasons are that these works are often carried out in complicated geological and hydrological conditions and safety risks in these works are characterized with imperceptibility, complexity, and instability [10]. As such, safety problems in tunnel construction should drive more researchers' concerns.

Previous literature identified numerous factors that potentially cause construction accidents [11-13]. Of these factors, workers' unsafe behaviors (WUBs) are the most salient $[11,14]$. Therefore, identifying the potential contributing factors to WUBs and then designing potent programs to cultivate workers' safety behavior are leading research topics in construction safety management [15-17]. Unsafe behaviors are not only the results of response process influenced by wide ranges of social, organizational, and management factors 
[18-21], but also the results of individuals' decision-making processes affected by self's psychological status or features $[15,22-25]$. Cognitive biases (CBs) are such a type of psychological factors that critically influence individuals' decision-making process of unsafe behaviors [25-27]. The concept refers to "systematic information-processing shortcuts that result in judgment errors" [28]. Prior studies pointed out that CBs could bring about managers' risk-taking behaviors. The reason is that different types of CBs can cause lower-level risk perceptions (RPs) and then lead to their risky decision-making [29-31]. As for the construction workers, Low et al. [26] simply highlighted that CBs as a whole can induce WUBs; however, more questions about the functions of CBs on WUBs are also triggered. For instance, do different types of CBs exert different effects on WUBs? And can RPs work as mediators in the relationships between CBs and WUBs as they do on managers' behaviors? Both questions need further examination.

As such, this study focuses on the aforementioned questions and further reveals the mechanism by which CBs influence WUBs. We selected three significant cognitive biases, namely, availability bias (AB), confirmation bias (FB), and overconfidence. The aims of this research are (1) to examine the relationships between the three CBs and WUBs and (2) to evaluate the mediating effects of RPs on the relationships between CBs and WUBs. The study can enrich the knowledge of CB and workers' safety behavior research. In addition, it also can help project managers and psychologists to design safety programs to improve worksite safety management.

\section{Literature Review and Conceptual Model}

2.1. CBs and Their Relationships with WUBs. CBs refer to a wide range of recurring reasoning tendencies that can cause deviations from the realistic facts $[32,33]$. These psychological tendencies indicate human's systematic analysis shortcuts in information-processing [28]. The term was initially introduced by Tversky and Kahneman [34] and they identified three CBs, including representativeness, availability, and adjustment and anchoring. Further, Kahneman [35] examined the origin of CBs. He differentiated human's thinking into two systematic processes: systematic process one depends on heuristics that were characterized with unconsciousness, effortlessness, intuitiveness, and inclination to biases; on the contrary, systematic process two relies on conscious, effort-cost, more rational, and statistical reasoning [34]. And he highlighted CBs often generate in the systematic process one [35], although follow-up researchers found that other factors, such as emotion and social influence, can also lead to CBs [33].

More researchers introduced CBs to their disciplines and conducted salient investigations including health-caring [36], management [29], forensic [37], software engineering [33], and strategic decision-making [32]. Thus, over $200 \mathrm{CBs}$ have been identified in previous studies [33]. Fleischmann [38] proposed a taxonomy of CBs and divided them into eight categories, including interest biases, stability biases, action-oriented biases, pattern recognition biases, perception biases, memory biases, decision biases, and social biases. The authors investigated the construction workers' $\mathrm{CBs}$ and identified three critical $\mathrm{CBs}$ in their safety judgment. They are $\mathrm{AB}, \mathrm{FB}$, and overconfidence. $\mathrm{AB}$ refers to a propensity that individuals overestimate the probabilities associated with events causing them to give excessive weightage on the information available leading them to err. $\mathrm{FB}$ is viewed as an inclination that personnel tend to misinterpret new information to support their prior beliefs. Overconfidence can be defined as an unwarranted faith in one's reasoning, judgments, and abilities in decision-making [28, 39].

According to the definition of CBs, prior studies demonstrated that $\mathrm{CBs}$ can cause the incorrect understanding of the situation and the self and then lead to improper behaviors $[25,29]$. In detail, $A B$ manifests that individuals interpret the context relying on the information that they are easy to recall. And the easy-to-recall information is always limited and induces erroneous and superficial behavior decision-making [33]. FB manifests that an individual confirms a new situation using the experienced ones; thus, the same behaviors, however, lead to unsatisfied safety results instead. Overconfidence manifests irrational confidence to handle confronted risks, which always leads to risk-taking behaviors [40]. As for the construction workers, no research has been found focusing on the relationships between the three CBs and unsafe behaviors. However, based on the above analysis, we can posit that there exist negative relationships between the three CBs and WUBs.

(i) Hypothesis ( $\mathrm{Ha} 1) . \mathrm{AB}$ is positively associated with construction WUBs

(ii) Hypothesis (Ha2). FB is positively associated with construction WUBs

(iii) Hypothesis (Ha3). Overconfidence is positively associated with construction WUBs

2.2. Risk Perceptions and Their Mediating Roles. Risk perception gradually draws scholars' attention in construction safety research [15]. The concept was initially proposed in social sciences research in the 1980s, most of which focused on judgment and decision-making [41]. Although no consistent and explicit definitions were documented in the existing literature, a widely accepted definition of RP is individuals' subjective judgment of risk [42-44]. Slovic et al. [43] further highlighted that the subjective judgment processes are complicated and influenced by diverse factors, including individual's beliefs, attitudes, feelings, social and cultural values, and dispositions when assessing risks or hazards. The dimensions of RP are the bases to evaluate this concept. Sjöberg [45] pointed out that individuals' intuitive risk judgment comprises two components, i.e. the cognitive component and the affective component. Earlier research demonstrated more concerns on the cognitive aspects, including probability (likelihood) of the risky events and the consequences (severity) the risky events caused 
$[46,47]$. Recently, researchers argued that the affective aspects should also be considered. For instance, Man et al. [48] developed a novel measurement for construction workers' RPs and validated three dimensions of the RPs, namely, probability, severity, and worry and unsafe.

RPs can be influenced by a wide range of psychological, social, institutional, and cultural variables, such as safety climate, social pressure, occupational features, and demographic characteristics $[43,49,50]$. Of these variables, CBs are salient antecedents of RPs $[30,51,52]$. In water security research, Kosovac and Davidson [52] validated that CBs are associated with lower risk scores. Zaiane and Moussa [53] argued that overconfidence and illusion of control reduced RPs when managers start a venture. According to the perceptive objects, we divided RP into two types, namely, environmental risk perception (ERP) and behavioral risk perception (BRP). ERP is a type of RP pertaining to natural and management environment, and BRP focuses on individuals' behaviors. Thus, we posited that the three CBs (i.e., $\mathrm{AB}, \mathrm{FB}$, and overconfidence) exert negative effects on RPs.

(i) Hypothesis (Hb1). AB is negatively associated with ERP

(ii) Hypothesis (Hb2). FB is negatively associated with ERP

(iii) Hypothesis ( $\mathrm{Hb} 3$ ). Overconfidence is negatively associated with ERP

(iv) Hypothesis ( $\mathrm{Hb} 4) . \mathrm{AB}$ is negatively associated with BRP

(v) Hypothesis (Hb5). FB is negatively associated with BRP

(vi) Hypothesis (Hb6). Overconfidence is negatively associated with BRP

Individuals' RPs guide the risk decision-making processes, and thus, erroneous and deviated RPs often lead to improper behaviors [49]. Existing studies in construction safety management demonstrated that RPs were predictors of WUBs $[15,26,54]$. For instance, Bohm and Harris [46] found that RPs were linked to driver's risk-taking behaviors. Xia et al. [15] further argued that RPs could act as job hindrance or job challenge and solely validated that RPs can be job hindrance that are negatively related to safety behaviors. Therefore, we posit that this paradigm also can be applied to workers during tunnel construction and there exist negative relationships between RPs and WUBs.

(i) Hypothesis (Hc1). ERP is negatively associated with WUBs

(ii) Hypothesis (Hc2). BRP is positively associated with WUBs

Based on the abovementioned hypotheses, we posit that RPs can be mediators in the relationships between CBs and WUBs. In detail, the hypotheses below can be drawn. (i) Hypothesis (Hd1). ERP mediates the relationship between $\mathrm{AB}$ and WUBs

(ii) Hypothesis (Hd2). ERP mediates the relationship between FB and WUBs

(iii) Hypothesis (Hd3). ERP mediates the relationship between overconfidence and WUBs

(iv) Hypothesis (Hd4). BRP mediates the relationship between $\mathrm{AB}$ and WUBs

(v) Hypothesis (Hd5). BRP mediates the relationship between FB and WUBs

(vi) Hypothesis (Hd6). BRP mediates the relationship between overconfidence and WUBs

Therefore, we hypothesized a conceptual framework for this study (see Figure 1).

\section{Research Method}

3.1. Questionnaire Design and Participations. The questionnaire was developed based on five-point Likert scales. The whole questionnaire consisted of four sections. Section $A$ was utilized to collect the demographic information of the surveyed workers, including age, enterprise type, education level, and tenure. Section $B$ was used to measure AB, FB, and overconfidence. The selected items were modified based on the prior studies $[55,56]$. Section $C$ was designed to measure RPs and scale items were adapted from the existing research $[15,48]$. In section $D$, seven items were used to capture WUBs. These items are the discussion results from eight experienced experts in tunnel construction management. Items in Sections $B, C$, and $D$ are presented in Table 1 .

This questionnaire was administered to tunnel construction workers in four projects, including tunnel engineering in Zhengzhou-Wanzhou railway, Metro Line 9 of Chongqing, and Metro Line 6 of Changsha. The survey was conducted by authors from July 2019 to September 2019. In order to include more construction workers, the survey was conducted with confidentiality and anonymity, such that these workers can express their true feelings. During this period, 320 questionnaires were released, and finally, 237 valid respondents were collected (odd $=74.1 \%$ ). The demographic information of these respondents is statistically presented in Table 2.

3.2. Data Analysis Procedures. We designed multi-step analytical processes on the collected data using Statistical Package for Social Science (SPSS) 23.0 software [57]. Firstly, Cronbach's alpha was selected to test the reliability of the data $[58,59]$. Then, six multiple regression models were established to stepwise-examine the impacts of CBs and RPs on WUBs. The models and corresponding explanations are presented in Table 3.

\section{Data Analysis}

4.1. Date Preprocessing. The descriptive statistics, reliability, and inter-correlations of all the variables are presented in Table 4. All the Cronbach's alpha values are greater than 


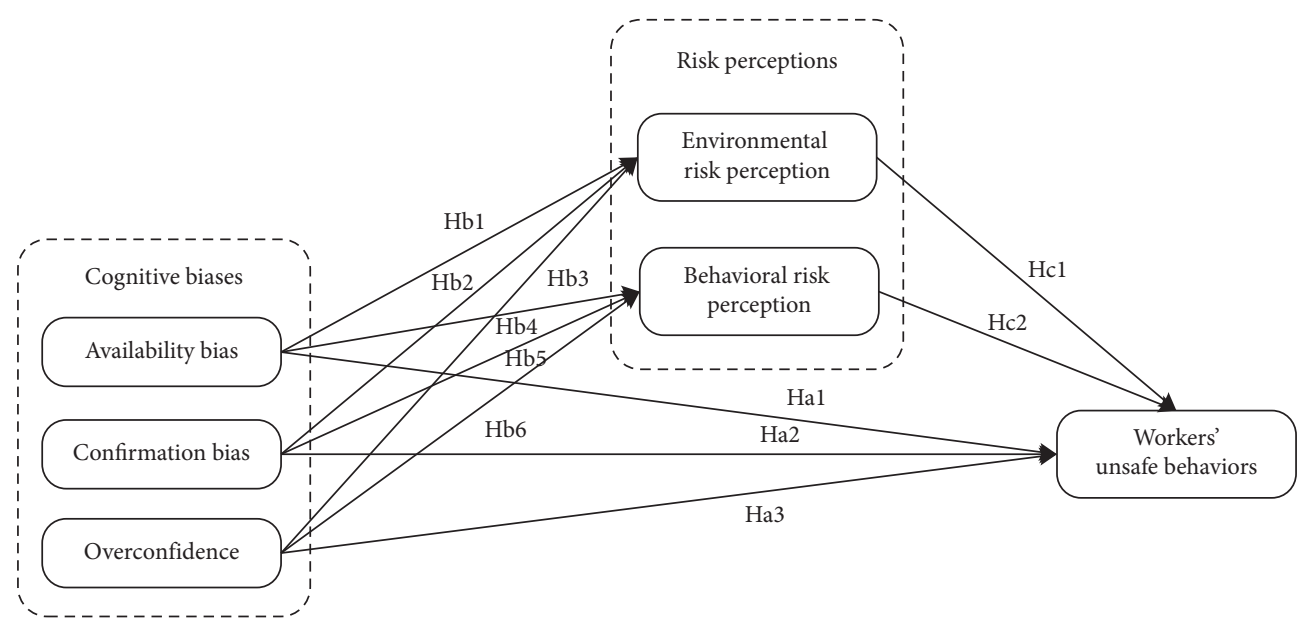

FIgURE 1: The hypothesized conceptual framework.

TABLE 1: Measurement items for CBs, RPs, and WUBs.

\begin{tabular}{|c|c|}
\hline Variables & Measurement items \\
\hline Availability bias & $\begin{array}{l}\text { I think coworkers' unsafe behaviors can be used for reference if the behaviors did not cause accident, because } \\
\text { they are more convenient. } \\
\text { I can continue to adopt unsafe behaviors as long as no accidents were caused, because these behaviors are } \\
\text { more convenient. } \\
\text { I always think there will be no accidents because no accidents occurred in the past few months. } \\
\text { I think they will handle the events because previous emergencies have been properly resolved. }\end{array}$ \\
\hline Confirmation bias & $\begin{array}{l}\text { My experiences tell me it is okay even though not wearing the PPE in some contexts. So, I cannot wear the } \\
\text { PPEs because the PPEs make me inconvenient. } \\
\text { My experiences tell me it is okay, even though slightly overloading the machine. So, I can overload the } \\
\text { machine when we need to rush to work. } \\
\text { Violating some regulations can hardly cause accidents. So, I am willing to take slight risks because these } \\
\text { behaviors can be energy-saving. } \\
\text { Some unrecommended behaviors hardly cause accidents. So, I am willing to take slight risks when we need to } \\
\text { rush to work. }\end{array}$ \\
\hline Overconfidence & $\begin{array}{l}\text { I can handle the works better and faster than my coworkers. } \\
\text { I am very skillful and can handle all unexpected situations even though I violate the regulations. } \\
\text { I am very familiar with the environment and can run away from risky situations even though I violate the } \\
\text { regulations. } \\
\text { I can handle all difficulties encountered during tunnel construction. }\end{array}$ \\
\hline $\begin{array}{l}\text { Environmental risk } \\
\text { perception }\end{array}$ & $\begin{array}{l}\text { My work is prone to safety accidents. } \\
\text { My job can be life-threatening. } \\
\text { There are uncontrollable risks in my work. }\end{array}$ \\
\hline
\end{tabular}

My unsafe behaviors have high probabilities of causing a safety incident.

My unsafe behaviors are likely to cause huge losses.
Behavioral risk perception $\quad$ My unsafe behaviors are easily discovered and I will be punished for them.

My unsafe behaviors can result in bad consequences that will affect my follow-up works.

I may ignore the warning signs and perform safety violations.

I may wear a safety helmet in a non-standard way.

Workers' unsafe behaviors

I may use tools and equipment with slight safety hazards.

For the convenience of work, I may use cargo transportations.

In order to catch up with the construction period, I may overload the mechanical equipment for a long time.

I may climb and sit at unsafe positions.

0.7, indicating that all the variables have higher internal consistency [57]. Unsafe behaviors are still prevalent among tunnel construction workers (mean of WUBs = 2.43). All CBs are at higher levels (all values > 2.44) and of the three workers' CBs, overconfidence has the highest score and FB has the lowest score. The workers' RPs need further improvement, and workers perceive more behavioral risks than environmental risks (mean of $\mathrm{BRP}>$ mean of ERP). In general, the relationships between CBs, RPs, and WUBs are statistically significant. According 
TABLE 2: Descriptive statistic of the respondents' demographic information.

\begin{tabular}{|c|c|c|c|}
\hline Variables & Values & Numbers & Percentages \\
\hline \multirow{5}{*}{ Age } & $18-25$ & 82 & 34.60 \\
\hline & $26-30$ & 64 & 27.00 \\
\hline & $31-40$ & 56 & 23.63 \\
\hline & $41-50$ & 21 & 8.86 \\
\hline & $>50$ & 14 & 5.91 \\
\hline \multirow{4}{*}{ Enterprise types } & General contractors & 119 & 50.21 \\
\hline & Subcontractors & 49 & 20.68 \\
\hline & Labor providers & 42 & 17.72 \\
\hline & Others & 27 & 11.39 \\
\hline \multirow{4}{*}{ Education level } & Junior high school and lower & 17 & 7.17 \\
\hline & Senior high school & 102 & 43.04 \\
\hline & Specialty college & 94 & 39.66 \\
\hline & Bachelor or higher & 24 & 10.13 \\
\hline \multirow{4}{*}{ Tenure } & $<5$ years & 75 & 31.65 \\
\hline & $5-15$ years & 87 & 36.71 \\
\hline & $15-25$ years & 43 & 18.14 \\
\hline & $>25$ years & 32 & 13.50 \\
\hline
\end{tabular}

TABLE 3: The six models and their explanation.

\begin{tabular}{|c|c|c|c|}
\hline Models & Model explanations & Objects & Hypotheses \\
\hline Model 1 & $\begin{array}{c}\mathrm{AB}, \mathrm{FB} \text {, and overconfidence were selected as the } \\
\text { independent variables. WUBs were the dependent } \\
\text { variable. }\end{array}$ & $\begin{array}{l}\text { Test the relationships between CBs with WUBs and } \\
\text { evaluate the significance of the three CBs in explaining } \\
\text { WUBs. }\end{array}$ & $\begin{array}{l}\mathrm{Ha} 1 ; \mathrm{Ha} 2 ; \\
\mathrm{Ha} 3\end{array}$ \\
\hline $\begin{array}{l}\text { Model } \\
2-1\end{array}$ & $\begin{array}{l}\mathrm{AB}, \mathrm{FB} \text {, and overconfidence were selected as the } \\
\text { independent variables. ERP was the dependent variable. }\end{array}$ & $\begin{array}{l}\text { Test the relationships between CBs with ERP and } \\
\text { evaluate the significance of the three CBs in explaining } \\
\text { ERP. }\end{array}$ & $\begin{array}{l}\mathrm{Hb} 1 ; \mathrm{Hb} 2 \\
\mathrm{Hb} 3\end{array}$ \\
\hline $\begin{array}{l}\text { Model } \\
2-2\end{array}$ & $\begin{array}{l}\mathrm{AB}, \mathrm{FB} \text {, and overconfidence were selected as the } \\
\text { independent variables. } \mathrm{BRP} \text { was the dependent variable. }\end{array}$ & $\begin{array}{l}\text { Test the relationships between CBs with BRP and } \\
\text { evaluate the significance of the three CBs in explaining } \\
\text { BRP. }\end{array}$ & $\begin{array}{l}\mathrm{Hb} 4 \text {; } \mathrm{Hb} 5 \text {; } \\
\quad \mathrm{Hb} 6\end{array}$ \\
\hline Model 3 & $\begin{array}{l}\text { ERP and BRP were selected as the independent } \\
\text { variables. WUBs were the dependent variable. }\end{array}$ & $\begin{array}{l}\text { Test the relationships between RPs with WUBs and } \\
\text { evaluate the significance of the two RPs in explaining } \\
\text { WUBs. }\end{array}$ & $\mathrm{Hc} 1 ; \mathrm{Hc} 2$ \\
\hline $\begin{array}{l}\text { Model } \\
4-1\end{array}$ & $\begin{array}{l}\mathrm{AB}, \mathrm{FB} \text {, overconfidence, and ERP were selected as the } \\
\text { independent variables. WUBs were the dependent } \\
\text { variable. }\end{array}$ & $\begin{array}{l}\text { Test the mediating effect of ERP in the relationships } \\
\text { between CBs and WUBs }\end{array}$ & $\begin{array}{l}\mathrm{Hd} 1 ; \mathrm{Hd} 2 \\
\quad \mathrm{Hd} 3\end{array}$ \\
\hline $\begin{array}{l}\text { Model } \\
4-2\end{array}$ & $\begin{array}{l}\mathrm{AB}, \mathrm{FB} \text {, overconfidence, and } \mathrm{BRP} \text { were selected as the } \\
\text { independent variables. WUBs were the dependent } \\
\text { variable. }\end{array}$ & $\begin{array}{l}\text { Test the mediating effect of BRP in the relationships } \\
\text { between CBs and WUBs. }\end{array}$ & $\begin{array}{l}\text { Hd4; Hd5; } \\
\quad \text { Hd6 }\end{array}$ \\
\hline
\end{tabular}

TABLE 4: Means, SD, reliability, and intercorrelations of all the variables.

\begin{tabular}{lcccccccccc}
\hline Variables & Means & S.D. & Cronbach's alpha & 1 & 2 & 3 & 4 & 5 \\
\hline Availability bias & 2.65 & 0.80 & 0.820 & 1 & - & - & - & - & - \\
Confirmation bias & 2.44 & 0.80 & 0.871 & $0.415^{*}$ & 1 & - & - & - & - \\
Overconfidence & 3.21 & 0.70 & 0.894 & 0.326 & 0.367 & 1 & - & - \\
Environmental risk perception & 3.38 & 0.79 & 0.856 & $-0.468^{* *}$ & $-0.424^{* *}$ & $-0.228^{* *}$ & 1 & - & - \\
Behavioral risk perception & 3.77 & 0.65 & 0.862 & $-0.228^{* *}$ & $-0.323^{* *}$ & $-0.442^{* *}$ & $0.387^{*}$ & 1 & - \\
Workers' unsafe behaviors & 2.43 & 0.82 & 0.911 & $0.416^{* *}$ & $0.342^{* *}$ & $0.437^{* *}$ & $-0.477^{* *}$ & $-0.521^{* *}$ & 1 \\
\hline
\end{tabular}

Notes: ${ }^{*} p<0.05 ;{ }^{* *} p<0.01$.

to the inter-correlations, it seems that ERP is more associated with $\mathrm{AB}$ and $\mathrm{FB}, \mathrm{BRP}$ is more linked to overconfidence, and WUBs are more influenced by RPs when compared to CBs. Besides, although not so significant, there exist statistical linkages between $A B$ and $F B$, and between ERP and BRP. 
4.2. Evaluating the Direct Influential Impacts. This study established four models to validate the direct relationships between CBs, RPs, and WUBs and the descriptions of the four models are presented in Table 3. After conducting multiple regression analyses in SPSS, the statistical results are shown in Table 5 .

Model 1 was employed to examine the direct relationships between the three $\mathrm{CBs}$ ( $\mathrm{AB}, \mathrm{FB}$, and overconfidence) and WUBs. Based on the analytical results (see Table 5), the direct relationships between CBs and WUBs are significant $(\chi 2=46.74, p<0.001) . \mathrm{AB}, \mathrm{FB}$, and overconfidence totally interpret 42.2 percent of WUBs. Besides, each of the CBs is positively correlated to WUBs, and thus, hypotheses $\mathrm{Ha} 1-\mathrm{Ha} 3$ are validated. Of the three CBs, FB is more related to WUBs $(\beta=0.438)$.

Model 2-1 and Model 2-2 were used to examine the direct relationships between $\mathrm{CBs}$ and RPs. As shown in Table 5, the direct relationship between $\mathrm{AB}, \mathrm{FB}$, overconfidence, and ERP was significant $(\chi 2=27.19, p<0.001) . A B$, $\mathrm{FB}$, and overconfidence totally interpret 25.0 percent of ERP. Each of the CBs is negatively associated with ERP, and thus, hypotheses $\mathrm{Hb} 1-\mathrm{Hb} 3$ are validated. However, when compared to $\mathrm{AB}$ and $\mathrm{FB}$, the relationship between overconfidence and ERP is less significant and also overconfidence explains less ERP $(p>0.05 ; \beta=0.264)$. Besides, the direct relationship between $\mathrm{AB}, \mathrm{FB}$, overconfidence, and $\mathrm{BRP}$ was significant $(\chi 2=31.06, p<0.001)$. AB, FB, and overconfidence totally interpret 27.3 percent of BRP. Each of the CBs is negatively associated with BRP, and thus, hypotheses $\mathrm{Hb} 4-\mathrm{Hb} 6$ are validated. However, when compared to overconfidence, the relationship between $\mathrm{AB}, \mathrm{FB}$, and ERP is less significant, respectively, and they also explain less BRP $(p=0.09, \beta=0.277 ; p=0.06, \beta=0.293)$.

Model 3 was constructed to examine the direct relationships between RPs and WUBs. According to Table 5, the direct relationships between RPs and WUBs are significant $(\chi 2=69.09, p<0.001)$. ERP and BRP totally interpret 34.7 percent of WUBs. Both RBs are negatively correlated with WUBs, and thus, hypotheses $\mathrm{Hc} 1-\mathrm{Hc} 2$ are validated. Besides, when compared to ERP, BRP interprets more WUBs $(\beta=0.434)$.

4.3. Evaluating the Mediating Effects. Two regression models were further established to evaluate the mediating roles of RPs in the relationships between CBs and WUBs (more explanation of models can be seen in Table 3 ). The analytical results are presented in Table 6 .

Model 4-1 was employed to examine the mediating roles of ERP in the relationship between CBs and WUBs. As can be seen in Table 6, the mediating effects of ERP are salient $(\chi 2=26.97, p<0.001)$. CBs together with ERP totally interpret 53.2 percent of WUBs. According to values of $\Delta \beta$, the mediating effects of ERP on the relationships between $A B$, $\mathrm{FB}$, and WUB are much stronger, which is consistent with the analyses about Model 2-1.

Model 4-2 was constructed to test the mediating effects of BER on the relationships between CBs and WUBs. As shown in Table 6, the mediating effects of BRP are salient $(\chi 2=29.38, p<0.001)$. CBs together with ERP totally interpret 49.3 percent of WUBs. Besides, when compared to $\mathrm{AB}$ and $\mathrm{FB}$, the mediating effects of ERP on the relationship between overconfidence and WUB are much stronger, which is consistent with the analyses about Model 2-2.

\section{Discussion}

5.1. The Construction Workers' BCs, RPs, and WUBs. This study surveyed 237 tunnel construction workers on their BCs, RPs, and WUBs in China. The statistical results demonstrate that CBs and WUBs are common phenomena among these workers and their RPs also need further improvement. These results are consistent with the prior studies. Unsafe behaviors or risk-taking behaviors are still critical factors of construction accidents in China [14, 60]. Han et al. [61] pointed out that construction workers often adopted habitual unsafe behaviors on China's construction worksite and this type of behaviors is characterized by lower risks, higher occurrence, and stability. In general, construction workers show lower risk perception [54, 62, 63]. Xia et al. [54] argued that RPs are salient factors contributing to construction accidents. Scholars interested in this topic still focus on the measurement of RPs and their effects on safety behaviors. Existing studies cannot provide a resilient model to explain the lower construction workers' RPs. Few studies have been found on the construction workers' CBs and this area needs more researchers' exploration.

5.2. Relationships between BCs, RPs, and WUBs. This study validated that there exist direct relationships between BCs, RPs, and WUBs. Construction workers' BCs can directly influence WUBs. This finding is consistent with prior studies in other fields [32, 33]. Low et al. [26] included cognitive bias as an antecedent in their construction workers' risk-taking behavior model. Igual and Santamaría [64] highlighted that overconfidence can lead to irrational investor behaviors. In this paper, we further selected three $\mathrm{CBs}$, i.e., $\mathrm{AB}, \mathrm{FB}$, and overconfidence, and found that they all directly influence WUBs. Workers' CBs also can be antecedents of workers' RPs. This finding is consistent with prior studies on team decision-making [28] and venture-starting [53,65]. In detail, we validated that $A B$ and $F B$ more likely influence ERP, and overconfidence more likely influences BRP. Two views might provide insight into this finding. Firstly, according to the definitions of $\mathrm{AB}$ and $\mathrm{FB}$, these two CBs often occur when individuals make judgments on external events. And construction workers might often use this type of process to evaluate environmental risks. Secondly, as highlighted earlier, tunnel engineering is often situated in complicated environmental contexts. As such, workers are more likely overconfident in their internal ability or skills other than risk identification on the external environment.

Workers' RPs were tested to be salient factors of WUBs. The linkages have been documented in some previous studies $[15,49]$. In this paper, RPs were divided into ERP and BRP and each of RPs is negatively associated with WUBs. 
TABLE 5: Statistical results of four models for direct effects.

\begin{tabular}{|c|c|c|c|c|c|c|}
\hline Variables & $R^{2}$ & $\Delta R^{2}$ & $F$ & $\beta$ & $t$ & Sig. \\
\hline \multicolumn{7}{|c|}{ Model 1 (WUB as dependent variable) } \\
\hline $\mathrm{AB}$ & 0.422 & 0.411 & $46.739^{* *}$ & 0.364 & $5.879^{* *}$ & 0.000 \\
\hline $\mathrm{FB}$ & - & - & - & 0.438 & $7.303^{* *}$ & 0.000 \\
\hline Overconfidence & - & - & - & 0.315 & $5.156^{* *}$ & 0.000 \\
\hline \multicolumn{7}{|c|}{ Model 2-1 (ERP as dependent variable) } \\
\hline $\mathrm{AB}$ & 0.250 & 0.242 & $27.193^{* *}$ & -0.285 & $-5.345^{* *}$ & 0.000 \\
\hline $\mathrm{FB}$ & - & - & - & -0.336 & $-3.849^{* *}$ & 0.000 \\
\hline Overconfidence & - & - & - & -0.264 & $-4.351^{*}$ & 0.073 \\
\hline \multicolumn{7}{|c|}{ Model 2-2 (BRP as dependent variable) } \\
\hline $\mathrm{AB}$ & 0.273 & 0.268 & $31.062^{* *}$ & -0.277 & $-6.262^{*}$ & 0.094 \\
\hline FB & - & - & - & -0.293 & $-4.740^{*}$ & 0.065 \\
\hline Overconfidence & - & - & - & -0.323 & $-4.471^{* *}$ & 0.000 \\
\hline \multicolumn{7}{|c|}{ Model 3 (WUB as dependent variable) } \\
\hline ERP & 0.347 & 0.344 & $69.092^{* *}$ & -0.302 & $-4.570^{* *}$ & 0.000 \\
\hline BRP & - & - & - & -0.434 & $-6.971^{* *}$ & 0.000 \\
\hline
\end{tabular}

TABLE 6: Statistical results of two models for mediating effects.

\begin{tabular}{|c|c|c|c|c|c|c|}
\hline Variables & $R^{2}$ & $\Delta R^{2}$ & $F$ & $\beta(\Delta \beta)$ & $t$ & Sig. \\
\hline \multicolumn{7}{|c|}{ Model 4-1 (WUB as dependent variable) } \\
\hline $\mathrm{AB}$ & 0.532 & 0.522 & $26.973^{* *}$ & $0.273(0.09)$ & $5.596^{* *}$ & 0.000 \\
\hline FB & - & - & - & $0.357(0.075)$ & $6.943^{* *}$ & 0.000 \\
\hline Overconfidence & - & - & - & $0.295(0.02)$ & $4.973^{* *}$ & 0.000 \\
\hline ERP & - & - & - & -0.243 & -4.320 & 0.000 \\
\hline \multicolumn{7}{|c|}{ Model 4-2 (WUB as dependent variable) } \\
\hline $\mathrm{AB}$ & 0.493 & 0.490 & $29.379^{* *}$ & $0.347(0.017)$ & $5.463^{* *}$ & 0.000 \\
\hline $\mathrm{FB}$ & - & - & - & $0.419(0.019)$ & $6.803^{* *}$ & 0.000 \\
\hline Overconfidence & - & - & - & $0.227(0.088)$ & $4.816^{* *}$ & 0.000 \\
\hline BRP & - & - & - & -0.407 & $-6.367^{* *}$ & 0.000 \\
\hline
\end{tabular}

We also validated that RPs act as mediators in the relationships between CBs and WUBs. The mediating effects of RPs on the relationship between CBs and individuals' unsatisfied behaviors can also be found in other fields. The mediating effects can function at the individual level or the group level. For instance, CBs influence managers' risky behaviors by decreasing managers' risk perception [32]. In team decision-making, Houghton et al. [28] highlighted that group cognitive biases can cause deviated RP and then lead to improper risky behaviors. Different CBs indirectly influence WUBs through different patterns. The mediating effects of ERP on the relationships between $A B, F B$, and WUBs are stronger than those on the relationship between overconfidence and WUBs. However, the mediating role BRP plays in the relationship between overconfidence and WUBs is more salient than it does in the linkages between $\mathrm{AB}, \mathrm{FB}$, and WUB. The possible reasons are akin to these we highlighted earlier in explaining the relationships between CBs and RPs.

5.3. Implications for Theory and Practice. This study provides a novel theoretical perspective on the relationships between CBs and WUBs, and the functions of RPs in these relationships. Unsafe behaviors are the salient factors contributing to construction accidents $[14,66]$. As such, a plethora of studies have been focused on the antecedents of unsafe/safety behavior. Existing research has confirmed a wide range of factors influencing WUBs, including social capital [18], safety climate [67], leader-member exchange [68], risk perception [54], etc. Although Low et al. [26] highlighted that CBs were important factors of workers' risktaking behavior, the relationships between CBs and WUBs were not further discussed. Construction workers are prone to influences from diverse CBs when they process safety information, and the relationships between different CBs and WUBs might be more complicated. In this study, we validated that the relationships between $\mathrm{CBs}$ and WUBs can be either direct or indirect. In detail, $A B, F B$, and overconfidence all can directly influence WUBs and indirectly influence WUBs through RPs. Besides, AB and FB indirectly affect WUBs more relying on ERP, and overconfidence indirectly affects WUBs more relying on BRP. This paper offers a novel theoretical reference for conceptualizing CBs and their relationships between RPs and WUBs.

This paper also can trigger the project managers' concern on CBs when making safety-related decisions. CBs are prevalent in workers' safety information-processing; 
therefore, some debiasing measures should be taken, such as providing more detailed safety information and including more experts to help workers' safety information decisionmaking. RPs act as mediators in the relationships between CBs and WUBs, which indicates that managers can motivate workers' safety behavior by improving their safety risk perception. As such, conducting more safety training and cultivating positive safety climate both can be effective management strategies.

5.4. Research Limitations and Future Directions. This study has three limitations. The first concern is that the survey utilizes a self-administered technique to measure CBs, RPs, and WUBs, which can lead the retrospective data to be slightly sensitive and dubiously accurate. The second worry is that we just considered three CBs in this study. Many other CBs also influence workers' safety information-processing, such as anchoring and adjustment, framing effects, etc. This paper provides a preliminary investigation on CBs; followup researchers can deepen this research by including more CBs. The third limitation is that this study tried to give some possible assumptions on why different CBs influence WUBs through different RPs. The assumptions need further validations. We also suggest that more researchers can work on the contributing factors to the CBs, which can provide bases for debiasing.

\section{Conclusion}

This article provides a theoretical insight into the impacts of cognitive biases (CBs) on the workers' unsafe behaviors (WUBs) during tunnel construction. We selected three prevalent $\mathrm{CBs}$, namely, availability bias (AB), confirmation bias (FB), and overconfidence, and examined the relationships between the three CBs and WUBs and the functions of RPs in these linkages. Several conclusions can be drawn from the aforementioned analyses.

Four multiple regression models were established to examine the direct relationships between CBs, RPs, and WUBs. CBs were validated as salient antecedents of WUBs and each of the three CBs is positively associated with WUBs. CBs can also be contributing factors of RPs. The relationships between $\mathrm{AB}, \mathrm{FB}$, and environmental risk perception (ERP) are more significant and overconfidence explains more BRP. Besides, the linkages between ERP, BRP, and WUBs were tested as significant.

Two other multiple regression models were further established to test the mediating effects of RPs. RPs were validated as mediators in the relationships between CBs and WUBs. However, the mediating roles of the two RPs are different. In detail, $\mathrm{AB}$ and $\mathrm{FB}$ can indirectly influence more WUBs though ERP, and overconfidence relies more on BRP.

The study was the first to examine the relationships between different CBs and WUBs in construction safety management. We also revealed the mediating effects of different RPs on the relationships between CBs and WUBs. The study can enrich the knowledge of $\mathrm{CB}$ and workers' safety behavior research. In addition, it also helps project managers and psychologists to design safety strategies to improve worksite safety management.

\section{Data Availability}

All data generated or used during the study are included within the manuscript.

\section{Conflicts of Interest}

The authors declare no conflicts of interest.

\section{Acknowledgments}

The work described in this paper was fully supported by China Innovation Funding (2017YFB1201204), Nature Science Fund of Hunan Province (2019JJ40407), and Central South University (CSU) Special Scholarship for Study Abroad.

\section{References}

[1] H. Lingard and S. M. Rowlinson, Occupational Health and Safety in Construction Project Management, Taylor \& Francis, Milton Park, UK, 2005.

[2] H. Chen, H. Li, Y. Wang, and B. Cheng, "A comprehensive assessment approach for water-soil environmental risk during railway construction in ecological fragile region based on AHP and MEA," Sustainability, vol. 12, no. 19, Article ID 7910, 2020.

[3] G. Shi, B. Cheng, and A. Li, "A mathematical model for calculating the "brittleness-ductility" drop coefficient of sandstone in mining zones," Discrete Dynamics in Nature and Society, vol. 2020, Article ID 2621672, 2020.

[4] MOHURD, Workplace Accident Notification of Building and Municipal Engineering, Ministry of Housing and Urban-Rural Development, Beijing, China, 2019, http://www.mohurd.gov. cn/wjfb/202006/t20200624_246031.html.

[5] BLS, Employer Reported Workplace Injuries and Illness-2018, Bureau of Labor Statistics, Washington, DC, USA, 2018, https://www.bls.gov/iif/oshsum.htm\#16Summary_Tables.

[6] LD, Summary of Occupational Safety and Health Statistics 2019, Labour Department, Hong Hong, China, https://www. labour.gov.hk/eng/osh/pdf/summary_OSH_Statistics_eng. pdf.

[7] MOM, Workplace Safety and Health Reports and Statistics, Ministry of Manpower, Havelock Road, Singapore, 2019, https://www.mom.gov.sg/workplace-safety-and-health/wshreports-and-statistics.

[8] B. Cheng, L. Wang, J. L. huang et al., "A computing model for quantifying the value of structural health monitoring information in bridge engineering," Mathematical Problems in Engineering, vol. 2020, Article ID 8260909, 2020.

[9] W. Liu, T. Zhao, W. Zhou, and J. Tang, "Safety risk factors of metro tunnel construction in China: an integrated study with EFA and SEM," Safety Science, vol. 105, pp. 98-113, 2018.

[10] L. Y. Ding, C. Zhou, Q. X. Deng et al., "Real-time safety early warning system for cross passage construction in Yangtze Riverbed Metro Tunnel based on the internet of things," Automation in Construction, vol. 36, pp. 25-37, 2013.

[11] R. A. Luo, S. A. Hide, A. G. F. Gibb et al., "Contributing factors in construction accidents," Applied Ergonomics, vol. 36, no. 4, pp. 401-415, 2005. 
[12] Z. Gyi and W. Lv, "Developing efficient circularity for construction and demolition waste management in fast emerging economies: lessons learned from Shenzhen, China," Science of The Total Environment, vol. 724, Article ID 138264, 2020.

[13] B.-G. Hwang, M. Shan, and S. L. Phuah, "Safety in green building construction projects in Singapore: performance, critical issues, and improvement solutions," KSCE Journal of Civil Engineering, vol. 22, no. 2, pp. 447-458, 2018.

[14] W. Zhang, S. Zhu, X. Zhang, and T. Zhao, "Identification of critical causes of construction accidents in China using a model based on system thinking and case analysis," Safety Science, vol. 121, pp. 606-618, 2020.

[15] N. Xia, Q. Xie, X. Hu, X. Wang, and H. Meng, "A dual perspective on risk perception and its effect on safety behavior: a moderated mediation model of safety motivation, and supervisor's and coworkers' safety climate," Accident Analysis \& Prevention, vol. 134, Article ID 105350, 2020.

[16] L. Niu, S. Zheng, and L. Li, "Experimental study on the seismic behavior of masonry walls under offshore environment," Structures, vol. 28, pp. 433-445, 2020.

[17] W. Z. Wang, L. Li, and Y. Zhang, "Bond-slip model considering freeze-thaw damage effect of concrete and its application," Engineering Structures, vol. 201, Article ID 109831, 2019.

[18] S. Li, X. Wu, X. Wang, and S. Hu, "Relationship between social capital, safety competency, and safety behaviors of construction workers," Journal of Construction Engineering and Management, vol. 146, no. 6, Article ID 04020059, 2020.

[19] C. He, B. McCabe, G. Jia, and J. Sun, "Effects of safety climate and safety behavior on safety outcomes between supervisors and construction workers," Journal of Construction Engineering and Management, vol. 146, no. 1, Article ID 04019092, 2020.

[20] D. A. Patel and K. N. Jha, "Structural equation modeling for relationship-based determinants of safety performance in construction projects," Journal of Management in Engineering, vol. 32, no. 6, Article ID 05016017, 2016.

[21] P. Zhang, N. Li, D. Fang, and H. Wu, "Supervisor-focused behavior-based safety method for the construction industry: case study in Hong Kong," Journal of Construction Engineering and Management, vol. 143, no. 7, Article ID 05017009, 2017.

[22] G. Ye, H. Yue, J. Yang et al., "Understanding the sociocognitive process of construction workers' unsafe behaviors: an agent-based modeling approach," International Journal of Environmental Research and Public Health, vol. 17, no. 5, Article ID 1588, 2020.

[23] B. Cheng, J. Li, V. M. Tam, M. Yang, and D. Chen, "A BIMLCA approach for estimating the greenhouse gas emissions of large-scale public buildings: a case study," Sustainability, vol. 12, no. 2, Article ID 685, 2020.

[24] Z. Wang, L. Li, and Y. Zhang, "Reinforcement model considering slip effect," Engineering Structures, vol. 198, Article ID 109493, 2019.

[25] S. Hasanzadeh, J. M. De La Garza, and E. S. Geller, "Latent effect of safety interventions," Journal of Construction Engineering and Management, vol. 146, no. 5, Article ID 04020033, 2020.

[26] B. K. L. Low, S. S. Man, A. H. S. Chan, and S. Alabdulkarim, "Construction worker risk-taking behavior model with individual and organizational factors," International Journal of Environmental Research and Public Health, vol. 6, no. 8, Article ID 1335, 2019.
[27] L. Sheffer and P. Loewen, "Electoral confidence, overconfidence, and risky behavior: evidence from a study with elected politicians," Political Behavior, vol. 41, no. 1, pp. 31-51, 2019.

[28] S. M. Houghton, M. Simon, K. Aquino, and C. B. Goldberg, "No safety in numbers," Group \& Organization Management, vol. 25, no. 4, pp. 325-353, 2000.

[29] A. Rashid and H. Boussabiane, "Conceptualizing the influence of personality and cognitive traits on project managers' risktaking behaviour," International Journal of Managing Projects in Business, 2019.

[30] M. Simon, S. M. Houghton, and K. Aquino, "Cognitive biases, risk perception, and venture formation," Journal of Business Venturing, vol. 15, no. 2, pp. 113-134, 2000.

[31] W. S. Hersing, "Managing cognitive bias in safety decision making: application of emotional intelligence competencies," Journal of Space Safety Engineering, vol. 4, no. 3, pp. 124-128.

[32] C. Acciarini, F. Brunetta, and P. Boccardelli, "Cognitive biases and decision-making strategies in times of change: a systematic literature review," Management Decision, 2020.

[33] R. Mohanani, I. Salman, B. Turhan, P. Rodriguez, and P. Ralph, "Cognitive biases in software engineering: a systematic mapping study," 2018, http://arxiv.org/abs/1707. 03869.

[34] A. Tversky and D. Kahneman, "Judgment under uncertainty: heuristics and biases," Science, vol. 185, pp. 1124-1131, Article ID 4157, 1974.

[35] D. Kahneman, Thinking, Fast and Slow, Macmillan, New York, NY, USA, 2011.

[36] G. Krebs, V. Pile, S. Grant, M. Degli Esposti, P. Montgomery, and J. Y. F. Lau, "Research review: cognitive bias modification of interpretations in youth and its effect on anxiety: a metaanalysis," Journal of Child Psychology and Psychiatry, vol. 59, no. 8, pp. 831-844, 2018.

[37] G. S. Cooper and V. Meterko, "Cognitive bias research in forensic science: A systematic review," Forensic Science International, vol. 297, pp. 35-46, 2019.

[38] M. Fleischmann, M. Amirpur, A. Benlian, and T. Hess, "Cognitive biases in information systems research: a scientometric analysis," in Proceedings of the 22nd European Conference on Information Systems ECIS 2014, Tel Aviv, Israel, June 2014.

[39] M. J. Kinsey, S. M. V. Gwynne, E. D. Kuligowski, and M. Kinateder, "Cognitive biases within decision making during fire evacuations," Fire Technology, vol. 55, no. 2, pp. $465-485,2019$.

[40] C.-W. Chen and M. Koufaris, "The impact of decision support system features on user overconfidence and risky behavior," European Journal of Information Systems, vol. 24, no. 6, pp. 607-623, 2015.

[41] T. M. Marshall, "Risk perception and safety culture: tools for improving the implementation of disaster risk reduction strategies," International Journal of Disaster Risk Reduction, vol. 47, Article ID 101557, 2020.

[42] P. Slovic, B. Fischhoff, and S. Lichtenstein, "Why study risk perception?” Risk Analysis, vol. 2, no. 2, pp. 83-93, 1982.

[43] B. Pandit, A. Albert, Y. Patil, and A. J. Al-Bayati, "Impact of safety climate on hazard recognition and safety risk perception," Safety Science, vol. 113, pp. 44-53, 2019.

[44] T. Aven and O. Renn, "On risk defined as an event where the outcome is uncertain," Journal of Risk Research, vol. 12, no. 1, pp. 1-11, 2009.

[45] L. Sjöberg, "Worry and risk perception," Risk Analysis, vol. 18, no. 1, pp. 85-93, 1998. 
[46] J. Bohm and D. Harris, "Risk perception and risk-taking behavior of construction site dumper drivers," International Journal of Occupational Safety and Ergonomics, vol. 16, no. 1, pp. 55-67, 2010.

[47] A. Perlman, R. Sacks, and R. Barak, "Hazard recognition and risk perception in construction," Safety Science, vol. 64, pp. 13-21, 2014.

[48] S. S. Man, A. H. S. Chan, and S. Alabdulkarim, "Quantification of risk perception: Development and validation of the construction worker risk perception (CoWoRP) scale," Journal of Safety Research, vol. 71, pp. 25-39, 2019.

[49] E. N. Chaswa, I. B. M. Kosamu, S. Kumwenda, and W. Utembe, "Risk perception and its influencing factors among construction workers in Malawi," Safety, vol. 6, Article ID 33, 2 pages, 2020.

[50] M. Namian, A. Albert, and J. Feng, "Effect of distraction on hazard recognition and safety risk perception," Journal of Construction Engineering and Management, vol. 144, no. 4, Article ID 04018008, 2018.

[51] A. Kosovac and B. Davidson, "Is too much personal dread stifling alternative pathways to improving urban water security?" Journal of Environmental Management, vol. 265, Article ID 110496, 2020.

[52] P. Baybutt, "Cognitive biases in process hazard analysis," Journal of Loss Prevention in the Process Industries, vol. 43, pp. 372-377, 2016.

[53] S. Zaiane and F. Ben Moussa, "Cognitive biases, risk perception, and individual's decision to start a new venture," International Journal of Service Science, Management, Engineering, and Technology, vol. 9, no. 3, pp. 14-29, 2018.

[54] N. Xia, X. Wang, M. A. Griffin, C. Wu, and B. Liu, "Do we see how they perceive risk? An integrated analysis of risk perception and its effect on workplace safety behavior," Accident Analysis \& Prevention, vol. 106, pp. 234-242, 2017.

[55] B. Fu, "Studies on the relationship among the knowledge staffs' cognitive biases," Job Satisfaction and Turnover Intention in the New High-Tech Enterproses, Liaoning University, Shenyang, Liaoning, China, 2015.

[56] H. Lin, A Study on the Realtionship between Cognitive Bias Unsafe Behavior of Construction Workers, Tianjin University of Technology, Tianjin, China, 2016.

[57] J. Pallant, SPSS Survival Manual, McGraw-Hill Education, New York, NY, USA, 2013.

[58] J. C. Nunnally, Psychometric Theory 3E, Tata McGraw-Hill Education, New York, NY, USA, 1994.

[59] A. P. C. Chan, A. A. Javed, F. K. W. Wong, C. K. H. Hon, and S. Lyu, "Evaluating the safety climate of ethnic minority construction workers in Hong Kong," Journal of Professional Issues in Engineering Education and Practice, vol. 143, no. 4, Article ID 04017006, 2017.

[60] S. Guo, J. He, J. Li, and B. Tang, "Exploring the impact of unsafe behaviors on building construction accidents using a Bayesian network," International Journal of Environmental Research and Public Health, vol. 17, no. 1, Article ID 221, 2020.

[61] Y. Han, Q. Mei, S. Liu, and Y. Sun, "Formation of construction workers' habitual unsafe behaviors and factors influencing it," China Safety Science Journal, vol. 25, no. 8, pp. 29-35, 2015.

[62] Y. P. Huang, X. Q. Wang, R. X. Ding, and N. N. Xia, "Risk perception, risk propensity, and unsafe behavior: an empirical study of workers in Chinese construction industry," in Proceedings of the IEEE International Conference on Industrial Engineering and Engineering Management, pp. 1121-1125, Bali, Indonesia, December 2016.
[63] L. Zhang, L. Ding, X. Wu, and M. J. Skibniewski, "An improved Dempster-Shafer approach to construction safety risk perception," Knowledge-Based Systems, vol. 132, pp. 30-46, 2017.

[64] M. G. Igual and T. C. Santamaría, "Overconfidence, loss aversion and irrational investor behavior: a conceptual map," International Journal of Economic Perspectives, vol. 11, no. 1, pp. 273-290, 2017.

[65] A. T. Robinson and L. D. Marino, "Overconfidence and risk perceptions: do they really matter for venture creation decisions?" International Entrepreneurship and Management Journal, vol. 11, no. 1, pp. 149-168, 2013.

[66] D. Fang, C. Zhao, and M. Zhang, "A cognitive model of construction workers' unsafe behaviors," Journal of Construction Engineering and Management, vol. 142, no. 9, Article ID 04016039, 2016.

[67] B. H. W. Guo, T. W. Yiu, and V. A. González, "Predicting safety behavior in the construction industry: Development and test of an integrative model," Safety Science, vol. 84, pp. 1-11, 2016.

[68] C. He, G. Jia, B. McCabe, and J. Sun, "Relationship between leader-member exchange and construction worker safety behavior: the mediating role of communication competence," International Journal of Occupational Safety and Ergonomics, pp. 1-13, 2019. 